\title{
DERECHOS DE NIÑOS, NIÑAS Y ADOLESCENTES FRENTE AL COVID-19
}

\author{
Rosa Elizabeth Guío Camargo \\ Universidad Católica de Colombia, Bogotá, Colombia \\ Recibido: 27/7/2020 - Aprobado: 3/8/2020 \\ doi: https://doi.org/10.26439/iusetpraxis2020.n50-51.5032
}

RESUMEN. En la presente ponencia se revisa la protección de los derechos de los niños, las niñas y los adolescentes en relación con la declaratoria de pandemia originada por el COVID-19. Así, se revisa esta incidencia como debilidad, oportunidad, amenaza y fortaleza. Como debilidad porque inicialmente las normas que ordenaron confinamientos nacionales no contemplaron grupos diferenciados. También puede verse como una oportunidad, pues al estar los padres en contacto por mucho más tiempo con los hijos se fomenta un ejercicio más consciente de la patria potestad, lo que permitiría construir su desarrollo de una forma más dialógica. Es una amenaza porque en muchos casos el confinamiento ha recrudecido las situaciones de violencia intrafamiliar y favorecido la deserción escolar, especialmente para aquellos niños, niñas y adolescentes que se encuentran en entornos más vulnerables. Finalmente, también puede observarse como una fortaleza, si se tiene en cuenta que el escenario de confinamiento social pone a prueba a cada país en relación con el cumplimiento y la efectividad de los derechos de la infancia y la adolescencia.

PALABRAS CLAVE: derechos de los niños, las niñas y los adolescentes / confinamiento social / efectividad del derecho

\section{RIGHTS OF BOYS, GIRLS AND ADOLESCENTS WITH REGARD TO THE COVID-19}

ABSTRACT. This presentation reviews the protection of the rights of boys, girls and adolescents concerning the COVID-19 pandemic declaration. Thus, this situation is analyzed based on four aspects: weaknesses, opportunities, threats and strengths. It is considered a weakness because the initial national lockdown rules did not took into account the different social groups. It can also be considered an opportunity, since parents are spending a lot more time with their children, which foster a more conscious exercise of parental authority and enable building a more dialogic development. It is a threat because, in many cases, lockdown has exacerbated intrafamilial violence and favored school dropouts, especially for those boys, girls and adolescents who live in the most vulnerable environments. Finally, it can also be a strength, if one takes into account that social lockdown tests each country's fulfillment and effectiveness of the rights of children and adolescents.

KEYWORDS: rights of boys / girls and adolescents / social lockdown

/ effectiveness of the law 


\section{INTRODUCCIÓN}

Desde comienzos de este año 2020 nos encontramos frente a una situación excepcional, pues la Organización Mundial de la Salud (2020) declaró, en marzo pasado, que el COVID-19, causada por el virus SARS-CoV-2, es una pandemia. En consecuencia, los gobiernos de casi todos los países del mundo se vieron en la necesidad de cerrar fronteras y ordenar confinamientos a las personas que estuvieran en su territorio, con unas muy contadas excepciones relacionadas básicamente con quienes prestan sus servicios en los hospitales y centros de salud, así como con quienes se encargan de los servicios básicos y de la provisión de alimentos.

Aunque no podemos negar que la finalidad de ordenar que la mayoría de las personas permanecieran en sus casas fue impedir o retrasar la propagación del virus, tampoco es menos cierto que la nueva realidad impactó sensiblemente la cotidianidad y, con ello, el ejercicio de los derechos. Así, uno de los grupos más afectados por ser de los que poco o nada se tuvo en cuenta en las naciones que inicialmente ordenaron el confinamiento fue el de los niños y adolescentes.

Queremos, por lo tanto, presentar en este artículo que la declaratoria del COVID-19 como una pandemia posee, por lo menos, cuatro aristas para su análisis con respecto a los derechos de los niños, las niñas y los adolescentes: puede verse como una debilidad, una oportunidad, una fortaleza o una amenaza.

\section{EL COVID-19 COMO DEBILIDAD PARA EL EJERCICIO DE LOS DERECHOS DE NIÑOS, NIÑAS Y ADOLESCENTES: DE REGRESO A LA IN-FANS}

Si revisamos los textos sobre historia de la infancia en Aries Philippe (1987) y sobre derecho de infancia por Galvis Ortiz (2006), García (1998) y Guío Camargo (2011 y 2014), podemos inferir que el camino para que a los niños, las niñas y los adolescentes se les reconociera como sujetos de derecho ha sido bastante largo: buena parte del siglo xx y lo corrido del siglo XXI se ha dedicado a la reflexión académica y a la creación de diferentes instrumentos jurídicos para garantizar el ejercicio pleno de los derechos de toda la infancia y la adolescencia (convenciones, protocolos facultativos, observaciones generales, constituciones, leyes de infancia y adolescencia, jurisprudencia, etcétera).

Pero estos importantes avances pueden verse ahora seriamente afectados, pues en muchos países las normas jurídicas mediante las cuales se ordenaron los cierres y confinamientos se refirieron a la población de forma genérica, sin tener en cuenta grupos diferenciados - adultos mayores; niños, niñas y adolescentes; personas en situación de discapacidad; entre otros-, de tal manera que se omite la atención a las necesidades de cada grupo en particular. 
En el caso de los niños, las niñas y los adolescentes, esta invisibilización -que equivale a que sus necesidades específicas no deban ser tomadas en cuenta al momento de la formulación de las políticas y los planes para el manejo y contención de la pandemia- puede tener consecuencias muy serias para el ejercicio activo de sus derechos, lo cual es violatorio de los mandatos contenidos en los artículos $2.1^{1}, 3.1^{2}, 4^{3}$ y $12^{4}$, a la luz de los cuales los Estados Partes deben garantizar el ejercicio pleno y efectivo de los derechos de todos los niños, las niñas y los adolescentes, y brindar los medios para que estos sean oídos, por sí mismos o mediante un representante o institución, en todos los asuntos que los afectan. Y, por supuesto, la declaratoria de pandemia por el COVID-19 es un asunto que afecta a la infancia y la adolescencia, aunque para cada uno habrá afectaciones diferentes.

Así, una es la situación de los niños más pequeños, que por efectos de la declaratoria de pandemia pueden ver vulnerado, por ejemplo, el acceso a su esquema de vacunación o a espacios donde se aprende a socializar con pares (jardines infantiles y guarderías). Otra, la de los niños que se hallan en situación de discapacidad, para quienes puede ser aún más complejo el acceso a la prestación de los servicios de salud física o mental requeridos. Los adolescentes pueden ver muy afectada la construcción de su espacio e identidad personal, especialmente si su entorno familiar es violento o, por efectos de la pandemia, se volvió aún más vulnerable (por ejemplo, si sus padres perdieron el empleo, se enfermaron o fallecieron como consecuencia del coronavirus). Si disgregamos por género, los riesgos de las niñas pueden ser, por ejemplo, el incremento de las tareas domésticas; y el de los niños, el hecho de que sean más fácilmente reclutados por grupos armados de delincuencia organizada o que se encuentran al margen de la ley.

1 “Los Estados Partes respetarán los derechos enunciados en la presente Convención y asegurarán su aplicación a cada niño sujeto a su jurisdicción, sin distinción alguna, independientemente de la raza, el color, el sexo, el idioma, la religión, la opinión política o de otra índole, el origen nacional, étnico o social, la posición económica, los impedimentos físicos, el nacimiento o cualquier otra condición del niño, de sus padres o de sus representantes legales".

2 “En todas las medidas concernientes a los niños que tomen las instituciones públicas o privadas de bienestar social, los tribunales, las autoridades administrativas o los órganos legislativos, una consideración primordial a que se atenderá será el interés superior del niño".

3 "Los Estados Partes adoptarán todas las medidas administrativas, legislativas y de otra índole para dar efectividad a los derechos reconocidos en la presente Convención. En lo que respecta a los derechos económicos, sociales y culturales, los Estados Partes adoptarán esas medidas hasta el máximo de los recursos de que dispongan y, cuando sea necesario, dentro del marco de la cooperación internacional".

4 “Los Estados Partes garantizarán al niño que esté en condiciones de formarse un juicio propio el derecho de expresar su opinión libremente en todos los asuntos que afectan al niño, teniéndose debidamente en cuenta las opiniones del niño, en función de la edad y madurez del niño.

Con tal fin, se dará en particular al niño oportunidad de ser escuchado, en todo procedimiento judicial o administrativo que afecte al niño, ya sea directamente o por medio de un representante o de un órgano apropiado, en consonancia con las normas de procedimiento de la ley nacional". 
Por ello, es necesario que los gobiernos de cada país, motu proprio o a instancias de organismos nacionales e internacionales de promoción y protección de los derechos de la niñez, revisen constantemente las normas jurídicas, las políticas y los planes para el manejo de la pandemia, siempre en función de reconocer que dentro del gran grupo "habitantes de una nación" hay diversidades que deben ser tomadas en cuenta, para que - al amparo del interés general- no terminen los derechos de cada uno como individuo en letra muerta.

\section{EL COVID-19 COMO OPORTUNIDAD PARA EL EJERCICIO DE LOS DERECHOS DE NIÑOS, NIÑAS Y ADOLESCENTES: UN NUEVO SIGNIFICADO DE LA PATRIA POTESTAD}

Como segundo punto de este escrito, queremos destacar que las declaratorias nacionales de confinamiento social implican un ejercicio mucho más consciente de la patria potestad, especialmente en el aspecto de la representación legal, y una oportunidad para construirla de forma dialógica y no impositiva. En este sentido, la cercanía actual entre padres e hijos que es consecuencia del confinamiento permite reforzar los lazos familiares en orden a un ejercicio consciente de los derechos y deberes entre los padres y madres y sus hijos.

Así, "originalmente en Roma la patria potestad era considerada como un poder del padre-varón sobre sus hijos" (Varsi, 2012, p. 290), y posteriormente se entendió como "la autoridad que se otorga a los padres sobre los hijos para dirigirlos y representarlos judicial y extrajudicialmente" (Valencia y Ortiz, 1995, p. 15). Asimismo:

Luego, con el reconocimiento de los niños, las niñas y los adolescentes como sujetos activos titulares de derechos, debemos entender hoy que en virtud del principio de autonomía progresiva que cobija la capacidad de goce (o capacidad negocial) de la infancia y la adolescencia, la patria potestad hoy debe contemplar tanto un ejercicio digno de la misma, que reconozca esta progresividad en la autonomía de los hijos. (Valencia y Ortiz, 2020, p. 136)

Es, por lo tanto, una facultad que hoy por hoy no posee un carácter vertical, sino horizontal, y privilegia el desarrollo de los intereses de los hijos más que los de los padres (Varsi, 2012, p. 291), con lo cual su carácter es en la actualidad más dialógico que impositivo (Guío Camargo, 2020, p. 207).

Por ende, el confinamiento social impuesto por las normas que buscan proteger a las personas de la propagación del COVID-19 puede ser, también, una oportunidad; pues esta cercanía física entre padres e hijos y el hecho de permanecer todos juntos en un mismo espacio por tanto tiempo implican, en la práctica, un ejercicio de la patria potestad muchísimo más consciente, sobre todo en el aspecto relacionado con la representación legal de los hijos, ya que los padres se ven mucho más involucrados con los negocios jurídicos en los cuales actúan como representantes legales de sus vástagos (como sería el caso 
de los que se celebran para la educación de los hijos en la etapa preescolar, primaria y secundaria). De suerte que este confinamiento se constituye en una oportunidad para construir un ejercicio de la patria potestad de una forma dialógica, tal y como lo propone la Convención sobre los Derechos del Niño (CDN) en sus artículos $5^{5}$ y $14.2^{6}$.

En tal sentido, el efecto del COVID-19 en contextos familiares sanos permite reforzar los lazos familiares pensando en los ambientes positivos, en orden a un ejercicio consciente de los derechos y deberes entre los padres, las madres y los hijos. Aquí se ve potenciada esa parte familiar, que podría observarse como una oportunidad.

Sin embargo, lo mismo no puede predicarse de contextos familiares violentos o vulnerables, donde este confinamiento es, de hecho, una amenaza para la efectividad de los derechos de los niños, las niñas y los adolescentes, punto del cual nos ocuparemos a continuación.

\section{EL COVID-19 COMO AMENAZA PARA LA EFICACIA DE LOS DERECHOS DE NIÑOS,} NIÑAS Y ADOLESCENTES: VIOLENCIA INTRAFAMILIAR, DESERCIÓN ESCOLAR, RECLUTAMIENTO DE NIÑOS Y DEFICIENCIAS EN LA PRESTACIÓN DE SERVICIOS DE SALUD PARA LA INFANCIA Y LA ADOLESCENCIA EN SITUACIÓN DE DISCAPACIDAD

Para nadie es un secreto que, aun cuando el fin perseguido por las declaratorias nacionales de confinamiento social fue la protección de la vida y la salud de los habitantes de cada uno de los países, ello ha tenido como efecto colateral el aumento de la violencia en el hogar, lo que, para el caso de los niños, las niñas y los adolescentes, se traduce en una amenaza directa para la efectividad y garantía de sus derechos, especialmente en cuanto a la agudización y aumento de los casos de violencia intrafamiliar; la deserción escolar por falta de herramientas para el acceso a la educación remota o la imposibilidad de acompañamiento por los padres; el reclutamiento de menores de edad para las filas de los grupos armados al margen de la ley, y el hecho de que muchos niños, niñas y adolescentes en situación de discapacidad pueden carecer de la atención requerida por parte de sus cuidadores, y también por parte de las instituciones prestadoras de los servicios de salud que esta población necesita de forma permanente. A continuación, presentaremos los aspectos más relevantes de cada uno de ellos.

5 “Los Estados Partes respetarán las responsabilidades, los derechos y los deberes de los padres o, en su caso, de los miembros de la familia ampliada o de la comunidad, según establezca la costumbre local, de los tutores u otras personas encargadas legalmente del niño de impartirle, en consonancia con la evolución de sus facultades, dirección y orientación apropiadas para que el niño ejerza los derechos reconocidos en la presente Convención".

6 “Los Estados Partes respetarán los derechos y deberes de los padres y, en su caso, de los representantes legales, de guiar al niño en el ejercicio de su derecho de modo conforme a la evolución de sus facultades". 


\section{Contextos de violencia intrafamiliar que se han agudizado}

Tal como lo señala la Organización de las Naciones Unidas (ONU), en el último año y antes de la declaratoria del COVID-19 como pandemia, un número aproximado de 243 millones de mujeres y niñas (de entre 15 y 49 años de edad) de todo el mundo han sufrido violencia sexual o física por parte de un compañero sentimental. Esta situación se ha recrudecido, pues debido al confinamiento muchas personas se han visto obligadas a convivir de forma permanente con sus agresores. Son dicientes los datos de la ONU, que reporta el aumento de las denuncias por violencia doméstica especialmente contra las mujeres y las niñas:

[En lo que va de este año] los teléfonos de asistencia en Singapur y Chipre han registrado un incremento de más del 30 \% en las llamadas. En Nueva Gales del Sur (Australia), los trabajadores de primera línea comunicaron un $40 \%$ más de solicitudes de casos de violencia. En Francia, los casos de maltrato aumentaron un $30 \%$ desde el inicio del confinamiento el 17 de marzo. (ONU, 2020b)

Latinoamérica no ha sido la excepción, ya que en el reporte de World Economic Forum (2020) se indica lo siguiente:

Antes de la pandemia casi 20 millones de mujeres y niñas eran víctimas de violencias como la física y la sexual, y en lo corrido de la misma, las cifras han sufrido un aumento considerable: en Argentina, las llamadas a las líneas de emergencia que reciben casos de violencia doméstica aumentaron en un $67 \%$; en Chile el aumento fue del 70 \% con relación al mismo periodo del año anterior; el estado brasileño de São Paulo reportó un aumento del $45 \%$; México señala que la violencia contra la mujer ha aumentado en un $25 \%$, Colombia reportó un aumento en las llamadas por violencia intrafamiliar del 130 \% y Perú reportó, durante los primeros 23 días de estado de emergencia, 8000 llamadas de auxilio por violencia en el hogar. (PNUD Perú, 2020)

Además, ha sucedido que en muchas zonas no ha sido posible para las víctimas de violencia acudir a la tutela efectiva de sus derechos, pues no tienen conocimiento de cómo hacerlo y, además, en muchos casos inicialmente las autoridades administrativas y judiciales tuvieron que suspender términos o dejar de funcionar. Frente a ello, en muchos países se habilitaron lugares alternos para realizar denuncias, líneas especiales y campañas que involucraron incluso a algunos almacenes de comercio de víveres como mecanismo de comunicación más cercano a las víctimas, para que estas pudieran, desde allí, denunciar la violencia ocurrida en el hogar.

Esta situación vulnera los derechos de todas las víctimas y, en especial, los de las niñas, quienes son, en una proporción mayor, expuestas a este tipo de riegos, tal y como lo reconocen el Comité para la Eliminación de la Discriminación contra la Mujer y el Comité de los Derechos del Niño, organismos que

señalan sistemáticamente que las prácticas nocivas están profundamente arraigadas en las actitudes sociales según las cuales se considera a las mujeres y las 
niñas inferiores a los hombres y los niños sobre la base de funciones estereotipadas. También ponen de relieve la dimensión de género de la violencia e indican que las actitudes y estereotipos por razón de sexo o de género, los desequilibrios de poder, las desigualdades y la discriminación perpetúan la existencia generalizada de prácticas que a menudo implican violencia o coacción. (Naciones Unidas, 2014)

\section{Deserción escolar por falta de herramientas para el acceso a la educación remota o imposibilidad de acompañamiento por los padres}

Otro de los aspectos que han impactado la efectividad y el ejercicio de los derechos para los niños, las niñas y los adolescentes es el cierre de los diferentes centros educativos. De acuerdo con los datos de la Organización de las Naciones Unidas para la Educación, la Ciencia y la Cultura (Unesco), más de 100 países tuvieron que cerrar temporalmente las escuelas, lo cual, para marzo del 2020, afectó a un número cercano a los 850 millones de niños en todo el mundo (Noticias ONU, 2020), "cifra que al 27 de julio del 2020 aumentó a 1058824335 niños, niñas y adolescentes, esto es, el 60,5\% del total de los estudiantes matriculados en todo el mundo" (Unesco, 2020a y 2020b).

Entre ellos, quizá hay dos grupos de niños, niñas y adolescentes para quienes tales cierres escolares representan una amenaza adicional: se trata de aquellos niños y niñas más pequeños que adelantaban su primer acercamiento al entorno escolar en jardines infantiles y guarderías; así como de aquellos niños, niñas y adolescentes que, en situaciones precarias, recibían la alimentación en su escuela. De acuerdo con un informe publicado por el Fondo de las Naciones Unidas para la Infancia (Unicef), "por lo menos 40 millones de niños menores de 5 años han visto interrumpido su proceso en jardines y guarderías, con lo que el desarrollo de sus habilidades sociales, emocionales y cognoscitivas se ha visto seriamente afectado" (2020); y, en consecuencia, se está privando a este grupo poblacional no solo de su derecho a la educación (artículos 28 y 29 de la CDN) ${ }^{7}$, sino de la atención diferenciada de sus necesidades (artículo 3) ${ }^{8}$.

7 “Artículo 28. 1. Los Estados Partes reconocen el derecho del niño a la educación y, a fin de que se pueda ejercer progresivamente y en condiciones de igualdad de oportunidades ese derecho, deberán en particular:

a) Implantar la enseñanza primaria obligatoria y gratuita para todos;

b) Fomentar el desarrollo, en sus distintas formas, de la enseñanza secundaria, incluida la enseñanza general y profesional, hacer que todos los niños dispongan de ella y tengan acceso a ella y adoptar medidas apropiadas tales como la implantación de la enseñanza gratuita y la concesión de asistencia financiera en caso de necesidad;

c) Hacer la enseñanza superior accesible a todos, sobre la base de la capacidad, por cuantos medios sean apropiados;

d) Hacer que todos los niños dispongan de información y orientación en cuestiones educacionales y profesionales y tengan acceso a ellas;

e) Adoptar medidas para fomentar la asistencia regular a las escuelas y reducir las tasas de deserción escolar. 
En cuanto al segundo grupo, no podemos desconocer que para muchos niños, niñas y adolescentes la posibilidad de asistir a la escuela les permitía, también, garantizar su alimentación. Así, el cierre de las escuelas como consecuencia de la declaración de la COVID-19 como una pandemia ha generado también un impacto en la alimentación infantil. Según datos de la Organización de las Naciones Unidas para la Alimentación y la Agricultura (FAO), "solo en América Latina y el Caribe, 85 millones de niños, niñas y adolescentes se benefician de los comedores escolares, y para 10 millones de ellos, la alimentación allí recibida correspondía a su comida principal" (ONU, 2020a). Tal situación vulnera no solo - como ya mencionamos- su derecho a la educación, sino también a la salud (artículo 24 de la CDN)9. Así:

2. Los Estados Partes adoptarán cuantas medidas sean adecuadas para velar por que la disciplina escolar se administre de modo compatible con la dignidad humana del niño y de conformidad con la presente Convención.

3. Los Estados Partes fomentarán y alentarán la cooperación internacional en cuestiones de educación, en particular a fin de contribuir a eliminar la ignorancia y el analfabetismo en todo el mundo y de facilitar el acceso a los conocimientos técnicos y a los métodos modernos de enseñanza. A este respecto, se tendrán especialmente en cuenta las necesidades de los países en desarrollo.

Artículo 29 1. Los Estados Partes convienen en que la educación del niño deberá estar encaminada a:

a) Desarrollar la personalidad, las aptitudes y la capacidad mental y física del niño hasta el máximo de sus posibilidades;

b) Inculcar al niño el respeto de los derechos humanos y las libertades fundamentales y de los principios consagrados en la Carta de las Naciones Unidas;

c) Inculcar al niño el respeto de sus padres, de su propia identidad cultural, de su idioma y sus valores, de los valores nacionales del país en que vive, del país de que sea originario y de las civilizaciones distintas de la suya;

d) Preparar al niño para asumir una vida responsable en una sociedad libre, con espíritu de comprensión, paz, tolerancia, igualdad de los sexos y amistad entre todos los pueblos, grupos étnicos, nacionales y religiosos y personas de origen indígena;

e) Inculcar al niño el respeto del medio ambiente natural.

2. Nada de lo dispuesto en el presente artículo o en el artículo 28 se interpretará como una restricción de la libertad de los particulares y de las entidades para establecer y dirigir instituciones de enseñanza, a condición de que se respeten los principios enunciados en el párrafo 1 del presente artículo y de que la educación impartida en tales instituciones se ajuste a las normas mínimas que prescriba el Estado".

8 "1. En todas las medidas concernientes a los niños que tomen las instituciones públicas o privadas de bienestar social, los tribunales, las autoridades administrativas o los órganos legislativos, una consideración primordial a que se atenderá será el interés superior del niño.

2. Los Estados Partes se comprometen a asegurar al niño la protección y el cuidado que sean necesarios para su bienestar, teniendo en cuenta los derechos y deberes de sus padres, tutores $u$ otras personas responsables de él ante la ley y, con ese fin, tomarán todas las medidas legislativas y administrativas adecuadas.

3. Los Estados Partes se asegurarán de que las instituciones, servicios y establecimientos encargados del cuidado o la protección de los niños cumplan las normas establecidas por las autoridades competentes, especialmente en materia de seguridad, sanidad, número y competencia de su personal, así como en relación con la existencia de una supervisión adecuada".

9 "1. Los Estados Partes reconocen el derecho del niño al disfrute del más alto nivel posible de salud y a servicios para el tratamiento de las enfermedades y la rehabilitación de la salud. Los Estados Partes se esforzarán por asegurar que ningún niño sea privado de su derecho al disfrute de esos servicios sanitarios. 
No podemos desconocer el hecho de que, aunque todos estamos en la misma pandemia, no todos contamos con las mismas herramientas para el acceso a esta educación remota. Algunos contarán con ordenadores y computadores en su casa, otros con celular, otros pedirán prestado en casas vecinas internet y otros no tienen esa posibilidad en lo absoluto. Entonces el escenario frente a la garantía del derecho a la educación de los niños, niñas y adolescentes se ve muy amenazado, pues justamente aquellos que pertenecen a entornos más vulnerables, son los que se encentran en gran riesgo de deserción escolar, o directamente excluidos, por no contar con herramientas tecnológicas adecuadas, que les permitan acceder a la escuela de forma remota, agudizándose, de esta forma, la desigualdad que ya existía antes del COVID-19. (ONU, 2020a)

\section{Amenabarro, Lapuente y Navarro (2020) señalan lo siguiente:}

Finalmente, otro aspecto que resulta incidiendo en el derecho la educación de los niños, las niñas y los adolescentes, es el cambio y/o aumento de carga laboral de sus padres y madres, razón por la cual a muchos se les hace imposible hacer el acompañamiento académico a los niños y niñas -especialmente a los más pequeños, y/o a aquellos que tienen necesidades educativas especiales-, por lo que, en algunos casos, se han visto en la necesidad de interrumpir la escolarización de sus hijos por alguna de estas circunstancias lo cual va a tener incidencia en su desarrollo.

\section{Reclutamiento de menores de edad para las filas de los grupos armados al margen de la ley}

En algunos países, la suscripción del Protocolo Facultativo de la Convención sobre los Derechos del Niño relativo a la Participación de Niños en Conflictos Armados (Guío

2. Los Estados Partes asegurarán la plena aplicación de este derecho y, en particular, adoptarán las medidas apropiadas para:

a) Reducir la mortalidad infantil y en la niñez;

b) Asegurar la prestación de la asistencia médica y la atención sanitaria que sean necesarias a todos los niños, haciendo hincapié en el desarrollo de la atención primaria de salud;

c) Combatir las enfermedades y la malnutrición en el marco de la atención primaria de la salud mediante, entre otras cosas, la aplicación de la tecnología disponible y el suministro de alimentos nutritivos adecuados y agua potable salubre, teniendo en cuenta los peligros y riesgos de contaminación del medio ambiente;

d) Asegurar atención sanitaria prenatal y postnatal apropiada a las madres;

e) Asegurar que todos los sectores de la sociedad, y en particular los padres y los niños, conozcan los principios básicos de la salud y la nutrición de los niños, las ventajas de la lactancia materna, la higiene y el saneamiento ambiental y las medidas de prevención de accidentes, tengan acceso a la educación pertinente y reciban apoyo en la aplicación de esos conocimientos;

f) Desarrollar la atención sanitaria preventiva, la orientación a los padres y la educación y servicios en materia de planificación de la familia.

3. Los Estados Partes adoptarán todas las medidas eficaces y apropiadas posibles para abolir las prácticas tradicionales que sean perjudiciales para la salud de los niños.

4. Los Estados Partes se comprometen a promover y alentar la cooperación internacional con miras a lograr progresivamente la plena realización del derecho reconocido en el presente artículo. A este respecto, se tendrán plenamente en cuenta las necesidades de los países en desarrollo". 
Camargo, 2016, p. 105), el inicio de procesos de negociación con grupos armados al margen de la ley y la suscripción de acuerdos de paz (Guío Camargo, 2018) no han impedido que, durante la pandemia desatada por la COVID-19, se continúe con el reclutamiento de menores de edad para la comisión de diversos hechos ilícitos.

Tal es el caso de Colombia, en donde la Procuraduría General de la Nación (2020) -organismo encargado constitucionalmente de la promoción y protección de los derechos humanos- denunció lo siguiente ante la Fiscalía General de la Nación:

El uso de menores de edad en la comisión de delitos, lesiones y homicidios de personas protegidas, actos de terrorismo, tortura y desplazamiento forzado del que han sido víctimas miles de niñas, niños, adolescentes y familias campesinas e indígenas, en medio de la pandemia por la COVID-19, a manos del Ejército de Liberación Nacional -ELN-, las disidencias de las antiguas FARC-EP, y otros 8 grupos armados ilegales.

Según los datos de la Coalición contra la Vinculación de Niñas, Niños y Jóvenes al Conflicto Armado en Colombia (Coalico) y de acuerdo con el monitoreo que realiza su Observatorio de Niñez y Conflicto Armado (ONCA), se evidenció que en dicho país, entre enero y mayo del 2020 , se incrementaron en un $113 \%$ las afectaciones vinculadas con reclutamiento de niños, niñas y adolescentes en relación con el mismo periodo del año 2019 (2020). Tales cifras demuestran que, pese a los avances jurídicos del país, en la práctica continúan los riesgos para las niñas, los niños y los adolescentes colombianos.

\section{Dificultades en la atención de las necesidades de niños, niñas y adolescentes en situación de discapacidad}

Al respecto, Alasuutari (2020) refiere lo siguiente:

Los niños, niñas y adolescentes en situación de discapacidad requieren una atención más especializada y directa por los cuidadores y pueden verse vulnerados doblemente, puesto que pude ocurrir que ya no cuenten con cuidadores especializados por la situación de confinamiento; o que las personas que realizaban tal cuidado deban ahora repartir su tiempo entre esta labor y otras - como el cuidado de más menores de edad, o de personas enfermas-, que no realizaban antes del confinamiento originado por el COVID-19. De acuerdo con datos del Banco Mundial, la atención a los niños, niñas y adolescentes en situación de discapacidad debe contemplar, entre otros, desafíos como: la falta de presupuestos para la intervención temprana y la educación inclusiva de la infancia y la adolescencia en situación de discapacidad; el estigma y la discriminación que marginan e invisibilizan sus necesidades; la falta de capacitación adecuada de sus profesores y la ausencia o dificultad para el acceso a de materiales especializados para trabajar integralmente en su educación; y el hecho de que muchos esfuerzos humanitarios no tienen en cuenta las especificidades de niños, niñas y adolescentes en situación de discapacidad. 
Finalmente, resaltamos que es importante tener en cuenta que la reconfiguración de las relaciones jurídicas con los niños pasa por reconocer todas las falencias o imposibilidades que están ocurriendo en estos momentos; y que no se trata de un grupo homogéneo, sino que, por el contrario, las diferencias en edad, desarrollo y situación familiar, emocional y económica de sus entornos son factores que deben considerarse para atender adecuadamente sus necesidades y propiciar, de esta forma, un verdadero ejercicio activo de la titularidad de derechos señalada en la CDN, así como en las diversas normas nacionales que, de manera directa o indirecta, resultan aplicables a este grupo poblacional.

\section{EL COVID-19 COMO FORTALEZA: UNA PRUEBA DEL VERDADERO ALCANCE DE LA AUTONOMÍA Y CAPACIDAD PROGRESIVA DEL EJERCICIO DE LOS DERECHOS DE LOS NIÑOS, LAS NIÑAS Y LOS ADOLESCENTES}

Las declaratorias nacionales de confinamiento social ponen a prueba el cumplimiento de cada país en cuanto al ejercicio de la capacidad negocial de los niños, las niñas y los adolescentes; e imponen la necesidad de que las regulaciones jurídicas relacionadas con los derechos de los consumidores tomen en cuenta a esta población como un importante sujeto de actuación jurídica. Por lo tanto, si quisiéramos darle una mirada de fortaleza a esta situación de confinamiento, es el hecho de que ella pone a prueba a cada país en cuanto al cumplimiento del reconocimiento de la capacidad negocial de niños, niñas y adolescentes, porque, al encontrarse estos muy entrelazados con los medios digitales o virtuales que antes tratábamos de evitar, hoy en día están muy relacionados con dichos medios. De hecho, las plataformas virtuales se han convertido en los medios que permiten la educación y la interacción remota de los niños, las niñas y los adolescentes con sus maestros, sus familiares y sus pares.

En tal sentido, los niños, las niñas y los adolescentes son sujetos de derecho que ahora -más que antes- se ven involucrados en las relaciones jurídicas de consumo: son ellos los que adquieren, a través de diversas plataformas, bienes o servicios diferenciados para sus necesidades, lo que pone en movimiento las cláusulas de las normas nacionales referidas a los derechos de los consumidores cuando estos son menores de edad y adquieren, por ejemplo, tecnología, ropa, cierto tipo de alimentos, etcétera.

No podemos desconocer que la interacción social mediada por las diversas plataformas tecnológicas y las redes sociales supone un enorme desafío frente al ejercicio del derecho a la intimidad. La CDN ha venido trabajando sobre el derecho a la intimidad de los adolescentes y ha señalado que estos tienen derecho a guardar sus historias clínicas $y$, aunque sean atendidos en confidencialidad por los médicos tratantes, es probable que en el actual escenario de pandemia ellos se vean seriamente afectados. La idea es que se imponga no tanto como una nueva norma que indique si la persona debe o no debe 
hacer eso, sino desde la propia educación del padre o de la madre de respetar el espacio individual de su hijo.

Enrique Varsi (2020), en el webinario internacional El derecho civil ante el COVID-19, acabada nuestra ponencia, hizo referencia a lo siguiente:

\begin{abstract}
Una de las grandes problemáticas que se han suscitado en los últimos meses es el cumplimiento del régimen de visita como derecho de los padres que no son tenedores, la realidad de las cosas llega a tener claro que no es un derecho de los padres sino de los niños de comunicarse con el padre que no convive. ¿Alguna reflexión sobre el particular que se haya generado en Colombia en la praxis?
\end{abstract}

Al respecto, consideramos que en la praxis colombiana lo que usualmente existe es un régimen de custodia en el que uno de los padres se queda con el niño y el otro realiza visitas. Este derecho se ha visto transgredido porque en algunas ciudades se han impuesto medidas como el "pico y género", en que solo se podía salir por géneros ciertos días. No obstante, se ha observado en la práctica que había padres que, teniendo el derecho de visita, lo ejercieron; pero se declaró la pandemia y se quedaron con el niño en sus hogares y ahora no quieren entregarlo al otro padre, y tampoco están permitiendo el acceso al niño a los jardines o escuelas por medios remotos. Las normas internas del país tipifican como un delito el ejercicio arbitrario de la custodia del vástago menor de edad. Se ha venido disparando la incidencia de este delito y lo que se va a necesitar, sobre todo, es insistir mucho en lo que se ha comentado acerca de que el derecho de visitas no es un derecho del padre, sino que es una garantía para que se cumpla el derecho del niño a tener una familia y a no ser separado. Por lo tanto, se ha de insistir en la educación y no cosificar al niño como si fuera un botín de guerra.

Soluciones jurídicas a la vista del delito correspondiente no las hay. Sin embargo, es un escenario importante y debemos hacer hincapié en las escuelas de padres respecto a lo que es -en realidad-el interés superior del niño, para poder capacitar a los progenitores y sacarles la idea de que -como ya mencionamos- sus hijos son trofeos de guerra.

\title{
CONCLUSIONES
}

La pandemia ocasionada por el COVID-19 obligó a los gobiernos de muchos países a decretar confinamientos cuya finalidad fue contener el avance del virus. Ello tuvo efectos en el ejercicio de los derechos de todas las personas. Empero, en el caso de los derechos de los niños, las niñas y los adolescentes, tal situación se analizó desde cuatro ópticas: como una debilidad, una oportunidad, una fortaleza y una amenaza.

Así, los confinamientos nacionales pueden observarse como una amenaza para el ejercicio de los derechos de la niñez y la adolescencia, pues las normas que ordenaron 
los confinamientos no disgregaron la afectación sobre los derechos de los diferentes grupos, lo cual implica, al amparo de estas normas de excepción, un retroceso en el reconocimiento de la titularidad activa de los derechos de los niños, las niñas y los adolescentes; y, en ese sentido, un regreso a la in-fans (sin voz), que por muchísimos años ha sido la constante del tratamiento de la niñez y la adolescencia por el derecho.

Por otro lado, el confinamiento obliga a un ejercicio mucho más consciente y dialógico de la patria potestad, por lo que en contextos familiares adecuados se propicia el ambiente para que los padres realicen un acompañamiento mucho más cercano a sus hijos durante las etapas de crecimiento en las que se encuentren estos últimos.

Sin embargo, no podemos desconocer que la situación descrita en el párrafo anterior no es la de muchos niños, niñas y adolescentes: para muchos de ellos, el confinamiento es una real amenaza para la eficacia de sus derechos por varias razones: i) la agudización de la violencia intrafamiliar; ii) el aumento de la deserción escolar en todos los niveles debido a la falta de herramientas para el acceso a la educación remota o la imposibilidad de realizar un acompañamiento por los padres o cuidadores; iii) en los países en los cuales persisten los conflictos armados internos, aumentó el número de personas menores de edad que fueron reclutadas para las filas de los grupos armados al margen de la ley, y iv) las dificultades que pueden surgir para la adecuada atención de las necesidades de niños, niñas y adolescentes en situación de discapacidad, ya sea por la ausencia de cuidadores especializados, o porque quienes realizaban tal labor deben atender ahora otras tareas adicionales.

Finalmente, y pese a que el panorama de la protección de los derechos de los niños, las niñas y los adolescentes no luce muy esperanzador en esta época de confinamiento, debemos señalar que también es un momento social que pone a prueba, en cada país y en el mundo entero, el verdadero alcance de la autonomía y capacidad progresiva del ejercicio de los derechos de los niños, las niñas y los adolescentes; y por ello sería también una fortaleza.

\section{REFERENCIAS}

Alasuutari, H. (20 de abril del 2020). Abordando la desigualdad en la educación durante y después del COVID-19. Los retos de la educación inclusiva. Recuperado de https://blogs.worldbank.org/es/education/abordando-la-desigualdad-en-laeducacion-durante-y-despues-del-covid-19-los-retos-de-la

Amenabarro, E. (Coord.), Lapuente, N. y Navarro, N. (2020). COVID-19. Desescolarización involuntaria: las familias y la escuela frente al espejo. Universidad del País Vasco, Escuela de Psicología. Recuperado de https://www.ehu.eus/documents/463823 6/14550176/0004.+IKERKETA.pdf/cb5a2e66-818b-5e1a-2c88-7f0adb1374ea 
Aries, P. (1987). El niño y la vida familiar en el antiguo régimen. Madrid: Taurus.

Coalición contra la Vinculación de Niñas, Niños y Jóvenes al Conflicto Armado en Colombia. (2020). Comunicado público: Llamado urgente al Estado colombiano para la implementación de medidas que garanticen la protección y acceso a los derechos de las niñas, los niños, adolescentes y jóvenes en todo el territorio nacional. Recuperado de http://coalico.org/prensa/comunicados-publicos/ comunicado-publico-llamado-urgente-al-estado-colombiano-para-laimplementacion-de-medidas-que-garanticen-la-proteccion-y-acceso-a-losderechos-de-las-ninas-los-ninos-adolescentes-y-jovenes-en-todo/

Fondo de las Naciones Unidas para la Infancia. (2020). Childcare in a global crisis: the impact of COVID-19 on work and family life. Recuperado de https://www. unicef-irc.org/publications/1109-childcare-in-a-global-crisis-the-impact-ofcovid-19-on-work-and-family-life.html

Galvis Ortiz, L. (2006). Las niñas, los niños y los adolescentes titulares activos de derechos. Mirada a Latinoamérica. Bogotá: Ediciones Aurora.

García, E. (1998). Infancia, ley y democracia en América Latina: una cuestión de justicia. Bogotá: Editorial Temis.

Guío Camargo, R. (2011). La constitucionalización del derecho de infancia y adolescencia en Colombia (tesis de maestría). Universidad Nacional de Colombia. Recuperado de http://www.bdigital.unal.edu.co/7046/2/06697329.2011.pdf

Guío Camargo, R. (2014). Evolución de la protección jurídica de la infancia entre 1887 y 2014: de los hijos de familia y los menores, al reconocimiento de los niños como sujetos activos titulares de derechos. En J. A. Bonivento y P. Lafont (Comps.), Jurista y maestro. Arturo Valencia Zea (t. II) (pp. 165-203). Bogotá: Universidad Nacional de Colombia.

Guío Camargo, R. (2016). La protección jurídica para los niños en el conflicto armado colombiano: de la Declaración de Ginebra al Protocolo Facultativo relativo a la Participación de Niños en los Conflictos Armados. Estándares internacionales para tener en cuenta en el proceso de paz colombiano. En T. Vivas (Ed.), Derechos humanos, paz y posconflicto en Colombia (pp. 105-124). Bogotá: Universidad Católica de Colombia.

Guío Camargo, R. (2018). Mandatos de protección del Estado colombiano a los niños en tiempos de conflicto y posconflicto. En VV. AA., Desafíos contemporáneos para la protección de derechos humanos en escenarios de posconflicto. Bogotá: Universidad Católica de Colombia.

Guío Camargo, R. (2020). Reflexiones sobre el estatuto jurídico de la infancia y la adolescencia colombiana y su aplicación en la justicia constitucional. Anuario Iberoamericano de Justicia Constitucional, 24(1), 207-236. https://doi.org/10.18042/ cepc/aijc. 24.07 
Naciones Unidas. Comité para la Eliminación de la Discriminación contra la Mujer y Comité de los Derechos del Niño. (2014). Recomendación general núm. 31 del Comité para la Eliminación de la Discriminación contra la Mujer y observación general núm. 18 del Comité de los Derechos del Niño sobre las prácticas nocivas, adoptadas de manera conjunta. Recuperado de https://www.acnur.org/ fileadmin/Documentos/BDL/2014/9925.pdf

Noticias ONU. (5 de marzo del 2020). Cierre de escuelas por el coronavirus: hay 850 millones de niños y jóvenes afectados. Recuperado de https://news.un.org/es/ story/2020/03/1470641

Organización de las Naciones Unidas. (18 de marzo del 2020a). El cierre de los comedores escolares por el coronavirus, un desafío para la alimentación en América Latina. Recuperado de https://news.un.org/es/story/2020/03/1471332

Organización de las Naciones Unidas. (7 de mayo del 2020b). Víctimas de la violencia doméstica atrapadas durante la pandemia. Recuperado de https://www.un.org /es/coronavirus/articles/un-supporting-trapped-domestic-violence-victimsduring-covid-19-pandemic

Organización de las Naciones Unidas para la Educación, la Ciencia y la Cultura. (2020a). Impacto del COVID-19 en la educación. Recuperado de https://es.unesco.org/ covid19/educationresponse

Organización de las Naciones Unidas para la Educación, la Ciencia y la Cultura. (2020b). Informe de seguimiento de la educación en el mundo. Inclusión y educación: todos sin excepción. Recuperado de https://gem-report-2020.unesco.org/es/ inicio/

Organización Mundial de la Salud. (24 de febrero del 2010). ¿Qué es una pandemia? Recuperado de https://www.who.int/csr/disease/swineflu/frequently_asked_ questions/pandemic/es/

PNUD Perú. (12 de abril del 2020). La otra pandemia: violencia en el hogar en tiempos de cuarentena. Recuperado de https://www.pe.undp.org/content/peru/es/ home/presscenter/articles/2020/la-otra-pandemia--violencia-en-el-hogaren-tiempos-de-cuarentena.html

Procuraduría General de la Nación. (9 de junio del 2020). Procurador denunció ante la Fiscalía reclutamiento ilícito y uso de menores en la comisión de delitos durante la pandemia del COVID-19. Recuperado de https://www.procuraduria.gov.co/ portal/Procurador-denuncio-ante-la-Fiscalia-reclutamiento-ilicito-y-uso-demenores-en-la-comision-de-delitos-durante-la-pandemia-del-covid-19.news

Valencia, A. y Ortiz, A. (1995). Derecho civil (t. V). Bogotá: Editorial Temis.

Valencia, A. y Ortiz, A. (2020). Derecho Civil (t. I). Bogotá: Editorial Temis.

Varsi, E. (2012). Tratado de derecho de familia. Lima: Gaceta Jurídica. 
Varsi, E. (2020). El derecho civil ante el COVID-19 [webinario]. Recuperado de https://us-lti. bbcollab.com/recording/4c29a5adbcf144568da6d33dd89b4a8e

World Economic Forum. (28 de abril del 2020). "Otra pandemia": violencia doméstica aumenta en América Latina durante cuarentena. Recuperado de https:// es.weforum.org/agenda/2020/04/otra-pandemia-violencia-domesticaaumenta-en-america-latina-durante-cuarentena/

\section{BIBLIOGRAFÍA}

De Mause, L. (1982). Historia de la infancia. Madrid: Alianza Editorial. 